\title{
Research on Railway Engineering Experiment Teaching Principles Based on Virtual Simulation Experiment Teaching__ Taking the Floating Slab Vibration Damping Track Virtual Experiment as an Example
}

\author{
Zhihui Zhu $^{1,2}$ Zhiping Zeng $^{1,2^{*}}$ Jing Liu ${ }^{1,2}$ Lili Liu $^{1,2}$ Lei Xu ${ }^{1,2}$ Wei Chen ${ }^{1,2}$ Wei Li ${ }^{1,2}$ \\ Jianyang Luo ${ }^{1,2}$ Joseph Eleojo Victor ${ }^{1,3}$ \\ 1. School of Civil Engineering, Central South University, Changsha, Hunan, 410075, China \\ 2. Experimental Teaching Center of Civil Engineering Virtual Simulation, Central South University, Changsha, Hunan, \\ 410075, China \\ 3. Department of Civil Engineering, Faculty of Engineering, Ahmadu Bello University, Zaria, Kaduna State, 800242, \\ Nigeria
}

\section{ARTICLE INFO}

Article history

Received: 23 March 2021

Revised: 8 May 2021

Accepted: 15 June 2021

Published Online: 30 October 2021

Keywords:

Virtual simulation

Experimental teaching

Railway engineering

Teaching principles

Floating slab vibration damping track

\section{ABSTRACT}

Virtual simulation teaching is an addendum to the experimental teaching mode of railway engineering, and the two teaching methods complement each other and merge with each other. In view of the current research, there is little discussion about the integration path of the two above. Based on the connotation and design of virtual simulation teaching, this research systematically expounds the integration of the real path and path optimization problems, and puts forward the railway engineering experimental teaching principles based on virtual simulation teaching. On the basis of this research, a virtual simulation experiment platform for vibration mechanics and its application in the floating slab vibration damping track was developed to make full use of three-dimensional modeling, virtual reality, human-computer interaction and other technologies, which can realistically simulate the vibration law and vibration damping effect of the rail transit system, and in the hope that the virtual simulation teaching can be widely used in the experimental teaching mode of railway engineering in the future.

\section{Introduction}

The development of computer networks and information technology has caused an exponential growth of global information in the form of information entropy. With the advent of the information age, blended learning modes such as online learning, mobile learning, and ubiquitous

learning have gradually innovated the traditional railway engineering experimental teaching accepting learning ${ }^{[1]}$. The new learning model triggered by the fragmentation of information has had a great impact on the experimental teaching of railway engineering ${ }^{[2]}$. Virtual simulation experiment teaching uses technologies such as virtual reality to construct illusory scenes, experimental conditions,

*Corresponding Author:

Zhiping Zeng,

School of Civil Engineering, Central South University, Changsha, Hunan, 410075, China; Experimental Teaching Center of Civil Engineering Virtual Simulation, Central South University, Changsha, Hunan, 410075, China;

Email:1877043690@qq.com 
realistic operation objects and learning content, as well as flexible and diverse interactive links, enabling students to simulate operations and independent learning anytime and anywhere, which is the modernization of railway engineering experimental teaching, and is a kind of new teaching mode for the development of railway engineering experimental teaching informatization ${ }^{[3,4]}$.

\section{The Scientific Connotation of Virtual Simulation Teaching}

\subsection{The Concept of Virtual Simulation Teaching}

Virtual simulation teaching combines virtual experiment technology with experiential teaching, where the learners use the human-computer interaction interface to adjust the parameter variables in the virtual experiment, and obtain the corresponding knowledge and skills by observing, summarizing and summarizing the results of computer simulation, which is similar to the more common expert system in teaching ${ }^{[5]}$.

\subsection{The Characteristics of Virtual Simulation Teaching}

Virtual simulation teaching can not only realize difficult or dangerous teaching experiments in reality with its good human-computer interaction interface and dynamic simulation program, but also save a lot of time, manpower and material resource costs that need to be spent in real experiments. The technical route of virtual simulation teaching mainly relies on computer technology and microcomputer technology, and the use of intelligent tools makes virtual simulation teaching have the characteristics of perception, interaction and immersion.

For example: for the steel spring floating slab vibration damping track in engineering, it is difficult for students to have a more intuitive understanding of the vibration law and dynamic characteristics in all directions after actual driving. The vibration transmission and the damping effect under different parameter conditions are also difficult to understand effectively. Due to the high traffic density, the dynamics test on the line is very dangerous, and it is difficult to carry out on-site experiments. At this time, the virtual simulation experiment teaching method can be used to achieve the effect of experimental teaching.

\subsection{Technical Methods for Realizing Virtual Simulation Teaching}

The technical methods for realizing virtual simulation teaching mainly include static models, virtual animations, simulation software, and software/ hardware interactive programs. The static model includes the construction of two-dimensional plane and three-dimensional model, and the available software includes Pro/E, Solidworks, etc. Virtual animation is the creation of frames or similar frames on the basis of static models, and the available software includes Unity3D, etc., with devices such as IE browsers, it can realize real-time remote login and use, and has low hardware and software requirements.

\section{Principles of Virtual Simulation Teaching Design}

\subsection{Principles of Scientific Inquiry}

The design of virtual simulation teaching follows the principles of scientific inquiry and experience. The principle of scientific inquiry means that teachers should pay attention to learners' ability to explore nature and society when designing virtual simulation teaching, and give full play to learners' logical reasoning and creative imagination of the external world. By creating situational problems that meet the teaching goals in the virtual situation, learners can make guesses and hypotheses centered on the problem, summarize and verify the results of their own observations, thereby construct a knowledge and skill system that meets their own language characteristics ${ }^{[6]}$.

\subsection{The Experiential Principle}

The experiential principle means that when learners participate in virtual simulation teaching, they can personally experience the virtual situation and understand and explore the surrounding things in a practical way. It includes three levels, namely the cognitive experience layer, the behavior experience layer and the emotional experience layer. The experiential principle emphasizes that learners should not only have cognitive and emotional input, but also pay attention to the impact of practical participation at the behavioral level on the learner's spirit of inquiry. Learners are not passive knowledge receivers, but active discoverers and sharers of knowledge.

\section{Establishment of Experimental Teaching Plan for Railway Engineering Based on VR Technology}

\subsection{Adhere to the Principle of Combining the Virtual with the Real}

Although virtual simulation experiment has many advantages, it can only be in the position of supplementary and auxiliary teaching. If the physical experiments are replaced by virtual simulation experiments, it will not 
only weaken the students' true feelings of the equipment, but also cause the students to have low eyesight and low hands, which will greatly reduce the training of practical skills. Thus, the virtual simulation project should always correspond to the various characteristics of the particular type of physical experiment in railway engineering.

For teaching effects that are not available or difficult to achieve in real situations (for example: floating slab vibration damping track vibration field test experiment, rail transit noise test experiment), or involving highrisk, extreme environment inaccessible, irreversible (for example: rail temperature experiments in severe cold areas, high-speed railway wheel-rail force test experiments), or high-cost, high-consumption teaching content (for example: track fatigue test experiments), it can be taken into consideration to build a virtual simulation experiment teaching laboratory or set up experimental projects ${ }^{[7,8]}$.

\subsection{Establish Two Working Modes of Practice and Assessment}

Based on virtual simulation teaching resources, on the one hand, students can independently learn online and perform simulation operations; on the other hand, teachers can also assess students and assess their mastery of this knowledge. Therefore, in resource construction, we should ensure that they have exercises and the two working modes of assessment.

The practice mode means that students carry out various training, experimental operations or simulation measurements under guidance or reminders, for the software will not give scores for experimental operation results, but based on the background management, it can record user operations, online time, etc. The test mode refers to the various trainings, experimental operations or simulation measurements that students independently carry out within a specified time. During this period, there will be no guidance or reminders. At the end, the system will automatically score and give experimental results, the user operations and online time will also be recorded by the system ${ }^{[9]}$.

\subsection{Establish Standardized and Comprehensively Designed Experiments with Appropriate Proportions}

The virtual simulation experiments developed at present are basically broadcast and single-threaded, lacking the arbitrariness, randomness and expansibility of interaction, which is not conducive to cultivating students' comprehensive design ability and innovation ability. Therefore, the construction of comprehensive design experiment projects should be increased ${ }^{[10]}$.

\subsection{Establish Technical Standards for Teaching Resource Development}

Resource performance requirements. The model should be realistic, optimized, and occupy a small space; the experimental project should retain the source code, engineering files, and executable files to facilitate later maintenance and upgrade; the experimental project should involve appropriate interaction links, decisionmaking judgments, and design considerations; It runs on computers, tablets and mobile phones; it is easy to integrate into a variety of applications and management platforms, which is conducive to access and sharing ${ }^{[11]}$. For example, when the virtual simulation experiment teaching system "Vibration Mechanics and Its Application in Floating slab Vibration Damping Track" was developed, the above-mentioned technical points were integrated, and a good teaching technology effect was achieved (Figure 1).

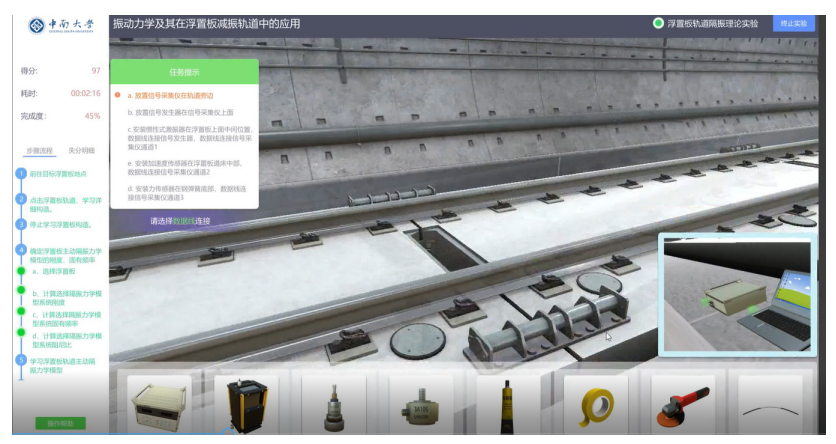

Figure 1. Railway Engineering Virtual Simulation Experiment Teaching

\subsection{Establishing Threshold access Standards for Teaching Resources}

The essence of the construction of the virtual simulation experiment teaching center, is the sharing of high-quality teaching resources. The open sharing of high-quality teaching resources is conducive to mobilizing students' enthusiasm for learning, leading demonstrations and radiating demonstrations. For this reason, it is necessary to establish a threshold access system for teaching resources, only high-level and high-quality teaching resources can be put on a public platform for open sharing.

\section{Application of Virtual Simulation Teaching in Experimental Teaching Mode of Railway Engineering}

\subsection{Basic Modes of Teaching}

Virtual simulation teaching belongs to the modern 
teaching mode, which is different from the experimental teaching mode of railway engineering. The difference between the two is reflected in the guiding ideology of teaching, the theoretical basis of teaching, the focus of teaching and the teaching methods. The modern teaching model emphasizes on student-centered use of network and multimedia systems in teaching, and its teaching theory follows modern management and other models, and conforms to the characteristics of activity teaching. While, the experimental teaching mode of railway engineering emphasizes teacher-centered and classroombased teaching. In the process of teaching, teachers need to monitor students' learning at all times (Figure 2).

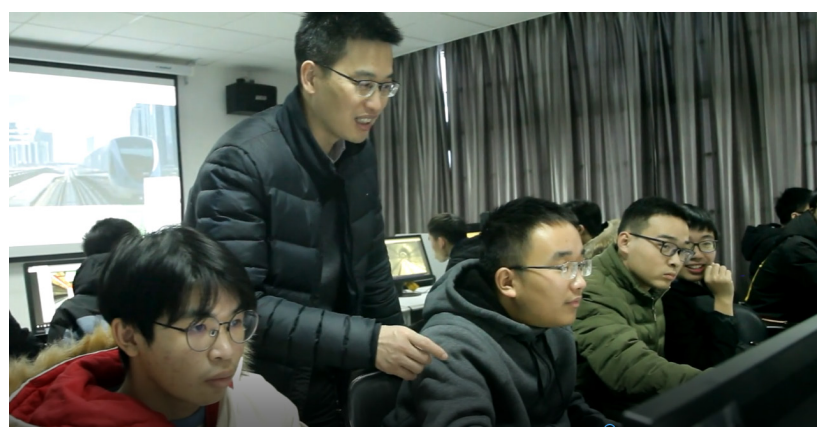

Figure 2. Railway Engineering Virtual Simulation Experiment Teaching

In the course of the experiment, the inquiry teaching method is adopted, with guidance and inquiry, students are motivated to actively explore the problems, so that students can form an independent construction of knowledge in the process of inquiry learning. Virtual simulation experiment of vibration mechanics and its application in floating slab track vibration reduction, is a comprehensive experimental project, that requires students to master and understand the knowledge of vibration mechanics courses and experimental technology. It can be combined with the vibration reduction of rail tracks in engineering. It makes the students to understand and feel that they can apply what they have learnt, and earnestly complete the inquiry process of the problem. With the help of the dynamic characteristics analysis, parameter analysis, and simulation functions of this experimental system, you can feel the impact of the vibration reduction design on the operation of rail tracks, so that students can have an in-depth understanding of vibration problems and solutions in the project, stimulate professional learning interest, and get in touch with industry background demand.

\subsection{Teaching Content}

With the virtual simulation experiment system, students can quickly build a three-dimensional scene of rail track, and intuitively feel the complex spatial relationship between the vehicle and the floating slab track vibration damping system, and understand the dynamic characteristics of the floating slab damping track system and the influence of different parameters on the damping effect.

With the computer technology, virtual simulation technology and Internet technology, the three-dimensional scene modeling, vibration analysis, vibration test, and vibration damping design experiment simulation of the steel spring floating slab vibration damping track system under different operating environments can be realized. Students can $\log$ on to the website of this virtual simulation experiment system to carry out online experiments and submit experiment reports. As shown in Figure 3, Students can start the sports car, excite the track, obtain the wheel-rail force function curve, the acceleration response curve of the ordinary track and the floating slab track, etc., and perform data processing, save the experimental data, and judge the floating slab track based on the measurement and data analysis results Whether driving safety, vibration reduction, and environmental vibration meet the requirements.

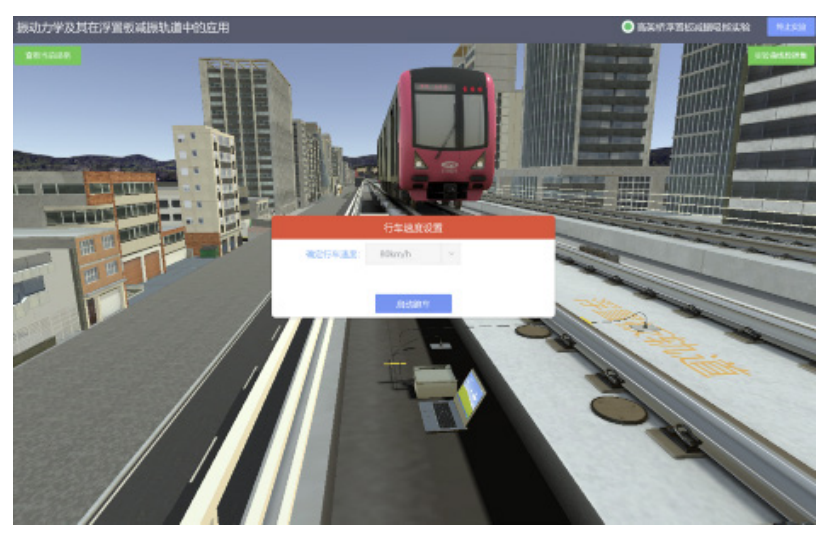

Figure 3. Start the train running experiment on the floating slab vibration damping track

For the experimental operation, the virtual experiment includes the vibration modeling of the steel spring floating slab track, the configuration of the vibration force source, the design of the vibration damping system and the analysis of the influence of the parameters on the vibration damping effect. When organizing experimental results and writing experimental reports, students are required to conduct a comprehensive analysis of the vibration isolation plan based on virtual experimental data and determine the recommended plan; according to the analysis of the experimental data, the impact of different parameters on the vibration damping effect and the 
surrounding environment is obtained.

\subsection{Teaching Experiment Effect}

For traditional track vibration experiments, the test components are required to be installed in advance during the field test, which has a long test cycle, large area, high cost, and affects line operation. By incorporating virtual simulation experiment teaching into railway engineering experiment teaching, the construction of threedimensional full-scale track system simulation models in different scenarios can transform high-cost, risky, and time-consuming field experiments into zero-cost virtual simulation experiments.

In the process of virtual simulation experiment teaching, students do not need to go with the timeconsuming and safety-related field tests, nor do they need to carry out vibration mechanics and floating slab track vibration reduction design with expensive and difficult indoor tests. With the test process of virtual simulation, they can deeply understand and master the necessary knowledge points; with the design of the vibration reduction scheme comparison process and the traintrack-tunnel/viaduct/station-stratum structure vibration propagation simulation process, and comprehensive engineering and operation effects, which can improve students' ability to compare and select rail vibration reduction schemes in real time

With the comparison and selection of vibration reduction design schemes, students can deeply understand that urban rail transit is a project that comprehensively considers complex factors such as engineering technology, operational safety, project cost, and harmonious environment, and has a significant impact on the production and life of residents along the line. The design process embodies a wealth of comprehensive values, strengthens and cultivates students' sense of mission and responsibility to learn mechanics well, and serve engineering practice, craftsmanship for excellence, and overall thinking and decision-making ability.

\section{Conclusions}

(1) To realize the adaptation of railway engineering experimental teaching to the new learning model and avoid the cognitive problems caused by the new learning model, it is necessary to improve and innovate the railway engineering experimental teaching model.

(2) Virtual simulation teaching, as an innovative teaching method that combines virtual experiments and experiential learning, not only expands the application of information technology in railway engineering experimental teaching, and makes the teaching environment no longer limited to the classroom. Based on the learner's knowledge and skills, it generates a teaching process that conforms to the learner's personality characteristics, so it is more suitable for the new learning mode under the background of educational information than the railway engineering experimental teaching.

(3) Although virtual simulation teaching has the incomparable advantages of the railway engineering experimental teaching mode, it is unable to trace all the indirect experience formed in the railway engineering experiment as the traditional railway engineering experimental teaching mode. Instead of the actual railway engineering experimental teaching mode, the integration engineering experiments is the development trend of railway engineering experimental teaching in the new era.

\section{Acknowledgment}

The research is financially supported by First-class Undergraduate Course Funding Project in Hunan ProvinceVirtual Simulation Experimental Teaching Course (Xiang Jiao Tong [2021] No. 28), Hunan Engineering Teaching Team) (Xiang Jiao Tong [2019] No. 370); National Experimental Teaching Center of Civil Engineering Virtual Simulation (Central South University) Open Project (202001); Education and Teaching Reform Project of Central South University (2020jy063), which is gratefully acknowledged by the authors.

\section{References}

[1] Wang Weidong, Xie Youjun, Lou Ping, et al. Exploration and practice of talent training of engineering specialty in rail transit industry [J]. Journal of Architectural Education in Institutions of Higher Learning, 2018, 27 (06): 36-43. application of virtual simulation teaching $[\mathrm{J}]$. China Education Information, 2019(06): 21-25.

[3] Zeng Zhiping, Zhu Zhihui, Wang Weidong, et al. Integration and Optimization of Railway Engineering Laboratory Resources under the Background of "Double First Class"[J]. Journal of Educational Theory and Management, 2020, 4(1): 76-79.

[4] Zhang Jialu, Li Xiaopeng, Ma Jun,Xing Bangsheng. Construction and sharing of "Internet +" virtual simulation experiment teaching resources for vehicle engineering specialty $[\mathrm{J}]$. China Education Information, 2021(03): 32-35.

[5] Chen Jinqiang, Zhao Liping, Xie Shaofeng, et al. of virtual simulation experiments with actual railway

[2] Li Xiong, Sun Luyao. The connotation, design and 
Design and practice of virtual simulation experiment teaching of traction power supply system for highspeed railway[J].Research in Higher Education of Engineering,2021(01):67-71+107.

[6] Kang Zhuang, Zhou Shunhua. Discussion on the team training model of engineering graduatesTake the railway engineering major of Tongji University as an example [J]. Degree and Graduate Education, 2013 (01): 19-22.

[7] Wang Wei, Xiang Jie, Wang Weidong. Research on Open Classroom Teaching in Colleges and Universities__Practical Questionnaire Analysis Based on Students' Perspective [J]. Modern University Education, 2018 (02): 96-102.

[8] Liu Yafeng, Su Li, Wu Yuanxi, et al. Principles and standards of virtual simulation teaching resources
construction[J]. Experimental Technology and Management, 2017, 34(05): 8-10.

[9] Zeng Zhiping, Zhu Zhihui, Wang Weidong, et al. Railway Engineering Experimental Teaching Research Based on the Combination of Field Experiment and Virtual Reality (VR) TechnologyTaking Central South University as an Example[J]. Review of Educational Theory, 2020, 3(3): 89-95.

[10] Zhang Tianlong, Zhu Zixin, Huang Jinwei. Development of railway signal equipment teaching platform based on virtual simulation[J].Modern Information Technology,2020,4(16):67-70+74.

[11] Ma Xiufei, Wang Baihua. Research on virtual simulation experiment teaching of high-speed railway train operation control system[J].Modern Computer (Professional Edition),2018(30):52-56. 